\title{
2006-50: THE FUTURE PRACTICE OF ENGINEERING
}

Harvey Lyons, Eastern Michigan University

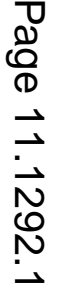




\section{THE FUTURE PRACTICE OF ENGINEERING}

\section{Introduction.}

The practice of engineering in the future is predicted to be exceedingly different than now. Educational institutions, and others who are affected by global technological changes, have started to prepare for those changes. This has fueled the Engineer of 2020 Project, sponsored by the National Academy of Engineering's Committee on Engineering Education. Their principal goal is to proactively modernize and reposition engineering curricula before a technological scare, such as the launch of Sputnik I in the 1950's, forced engineering colleges to hurriedly restructure their curricula.

\section{Development.}

In our initial research to determine current and future trends in engineering programs, we found many and different views of the future demands and practice of engineering. It was decided to research and survey several significant areas for this proposal: (1) Academic institutions that are currently reviewing trends towards new educational approaches; (2) Corresponding technical articles describing the trends; (3) Current efforts in academe; and (4) Industrial sources (both manufacturing and engineering-based) that have a direct/current need for engineering. We also used the Listserv to ask engineering educators to describe and recommend computer usage in their programs to learn of any trends in that area as well. Finally, we examined the classified ads for engineers from two local papers to determine the quantity and types of expertise desired.

\section{Trends and Perspectives}

In 2004, the National Academies Press published a paper written by the National Academy of Engineering entitled 'The Engineer of 2020: Visions of Engineering in the New Century'.(1) In the Preface, it stated that "Its principal focus is on the future of undergraduate engineering education in this country, although it is appreciated that to understand the full perspective, engineering practice and engineering education must be considered in a global context." The paper seeks to develop a vision for engineering by 2020; a second paper, which has not been completed, will examine what we need to do to prepare engineers for the future. Some of the factors listed as engendering change include nanotechnology, biotechnology, materials science, information and communications technology, environment and the aging population. It was stated that "The steady integration of technology in our infrastructure and lives calls for more involvement by engineers in the setting of public policy and in participation in the civic arena." The paper is quite extensive and, in its Conclusion, it states that the engineer of 2020 will be faced with myriad challenges and that they "...will be expected to anticipate and prepare for potential catastrophes such as biological terrorism; water and food contamination; infrastructure damage to roads, bridges, buildings and the electricity grid; and communications breakdown in the Internet, telephony, radio and television." Finally, it was noted that, due to the rapidly changing nature of modern knowledge, engineers 
“...must embrace continuing education as a career development strategy with the same fervor that continuous improvement has been embraced by the manufacturing community."

Dean Paul Peercy of the College of Engineering at the University of Wisconsin-Madison, presented a paper in June, 2004 entitled 'The Changing Face of Engineering. ${ }^{\text {(2) }}$ The paper noted that it is time to reevaluate the traditional approach to engineering education and that the engineers of tomorrow must be conversant in technical fields outside of their major discipline. Dr. Peercy stated that "Today, engineers in industry increasingly work in multidisciplinary product design teams that may include members with backgrounds in business, marketing, sales and other areas, in addition to science and engineering." $\mathrm{He}$ stated that "The ability to control the properties of materials at the nanoscale will give the engineer essentially unlimited choices, greatly expanding the possible materials solution." In conclusion, he noted that the boundaries between engineering subdisciplines and between science and engineering are disappearing, and "...leading all sub-disciplines back to their common foundations."

Dr. Philip Schmidt, Centennial Professor of Engineering and University Distinguished Teaching Professor at the University of Texas at Austin, presented a paper at the 2003 ASME Congress entitled 'Mechanical Engineering 2004-2005 Plan to the College' ${ }^{(3)}$ on the curriculum reform effort being undertaken at UT Austin. His disciplinary area is Mechanical Engineering, and he stated that "A successful Mechanical Engineering solution often requires an equal application of information, energy and materials technology. As such, the most important research areas in Mechanical Engineering are a blend of systems research and engineering science research." His department has identified specific and critical research thrusts which include: Mechanical Engineering at Small Scales; Designing Intelligent, Human Scale Systems; Efficient, Clean Energy Technologies; and Advanced Manufacturing and Processing. Another paper he copresented at the International Mechanical Engineering Conference and Exhibition in 2003 was entitled: 'Managing a Major Curriculum Reform Effort in a Large Research University. ${ }^{\left({ }^{(4)}\right.}$ Several recommendations were made in that paper: consolidate the separate freshman courses in graphics and intro to ME into a single course; convert machine elements into a project-centered experience; convert thermo course into a project-based thermal-fluid systems course. In conclusion, the authors stated that "The knowledge, skills, ethics and attitudes which we are trying to instill are prerequisites for leadership in the professional world."

Dean Eleanor Baum of the School of Engineering at The Cooper Union stated that, as Dean Paul Peercy of UW Madison noted, engineering programs should be fundamental at its core. (We note, as a graduate of that college, that The Cooper Union required all of its engineering majors to take many of the same fundamental courses so that all students will have a broad and/or general exposure to engineering disciplines). Dr. Baum suggested that EMU start with a mechanical engineering-based program that has a principal (project-based) design function and provide room for a specified variety of technical electives. Dr. Baum recommends that design opportunities and communication skills be introduced at the freshman level. 
Dr. Baum invited an alumnus, Dr. Clive Dym of Harvey Mudd College, to discuss 'The Evolution of Engineering Curricula'. ${ }^{(5)}$ Dr. Dym noted that his college has a common core in their curriculum that emphasizes engineering design and practice, and that "...design should be the backbone of engineering education and should be highly present in the curricula." Dr. G. Wayne Clough, President of Georgia Tech, was invited to discuss 'The Engineer of 2020' ${ }^{(6)}$ Dr. Clough noted that China graduates more engineers than any country in the world (about four-times as many as the U.S.) and that it is no longer true that the U.S. can attract the brightest minds from other countries into our engineering schools. He stated that the challenge '... is to find ways to reverse these trends and attract a major talent pool - otherwise, future decision makers will be looking to India and China for solutions.' Dr Clough called for new models in education emphasizing strong leadership, humanities and strong cooperative educational components; and that it is important to have a balanced general engineering degree to provide good 'springboard' into another career such as government, management, law, medicine, etc.

The Massachusetts Institute of Technology has established a Presidential Task Force on the Undergraduate Educational Commons in order to undertake a fundamental, comprehensive review of the common educational experience of our undergraduates in the early years of the $21^{\text {st }}$ century. A Boston Globe headline stated that 'MIT is reviewing its curriculum for a possible overhaul'. In the article, it noted that 'The Massachusetts Institute of Technology, widely considered the nation's top science and engineering school, is launching a two-year review of its undergraduate education, examining its required courses and other student experiences in light of new developments in science as well as the changing interests of students.' Dean of Science Robert Silby, who will chair the review committee, noted that 'There's much more biology in much of the research that we do' and 'There's much more interest in economics and social science among our students than there was 20 years ago.' The panel that will review the undergraduate curriculum will maintain a web site at http://web.mit.edu/committees/edcommons.

Drs. Edward Lee and David Messerschmitt of the University of California at Berkeley, in 'Engineering an Education for the Future', ${ }^{(7)}$ stated that ...'In smaller organizations, each engineer must assume a broader role, encompassing areas like marketing, standardization and law. The design of architecture, with relevant concepts and theories and many design experiences, should be a part of every designer's education. The pressure to focus education on vocational skills is huge. We should vigorously and unambiguously resist such pressure - no set of vocational skills has much longevity. An undergraduate education in electrical and computer engineering will be different for different students'.

A Workshop, sponsored by the National Science Foundation in 2002, produced a report entitled 'New Directions in Mechanical Engineering' ${ }^{(8)}$ The workshop included presentations in four core areas: Micro/Nano Technology, Biotechnology, Information Technology, and Ecology/Energy. Its recommendations stated '...that mechanical engineering needs to anticipate the development in these and other enabling technologies in order to rapidly exploit them in research and educational experiences that we offer to our future engineers'. Other recommendations include: 'Mechanical engineering faculty skills should be further expanded and enhanced to include additional expertise relevant to 
these newly emerging areas'. 'Mechanical engineering curricula should be reviewed and revised in light of these emerging areas. Curricula should include new material on atomic and molecular physics, quantitative biology, comprehensive (organic) chemistry, micro fabrication and modern computing'. 'Mechanical engineering laboratories should be reviewed and revised in light of these emerging areas'.

\section{Corresponding Articles}

The following technical articles discussed the demands and trends of the engineering graduate and changes in curriculum.

The Prism, in an article entitled '2020 It's Sooner Than you Think', ${ }^{(9)}$ notes that 'the future engineer must be prepared to work in a time in which what we now consider to be engineering is more likely to be done outside the United States... and perhaps, a time in which the United States is not the world's leading economic power.' Further, 'Engineering graduates may face more moral dilemmas in the workplace than ever before, as their employers go increasingly global.' It stated that 'The next generation of engineers may develop a deeper understanding of the moral dimensions of their profession, thanks to a movement to include ethics in the undergraduate curriculum at many engineering colleges. The trend is part of a larger goal of integrating liberal arts into the engineering curriculum.' Another Prism article, 'Engineering for Everyone', states that 'In a Technology-Driven Society, everyone needs to know about engineering, and more and more schools are teaching engineering courses to non-engineers. Students work in groups on small engineering projects, which largely focus on the design of everyday objects, but also touch many of engineering's disciplines.' An article in the New York Times, entitled 'Broaden Bioengineering Study Area' discussed the possibility that genetically engineered crops might have characteristics that could cause significant environmental harm. During an ASME-Sponsored Forum ${ }^{(10)}$ on the topic of global outsourcing of jobs, Ron Hira, an assistant professor of public policy at the Rochester Institute of Public Policy, said that unemployment of electrical and electronic engineers and computer hardware engineers is at unprecedented high levels and, for the first time, is exceeding the average U.S. civilian unemployment rate, which may be putting downward pressures on U.S. engineering salaries. In a recent article in the Ann Arbor News, Governor Jennifer Granholm announced a plan to double the rate of college graduates in Michigan over the next 10 years. Phil Gardener, director of Michigan State University Collegiate Employment Research Institute, said there will be more demand for engineers in the life sciences area and that there will be a '... shift in the kinds of engineering. It's not going to be automotive engineering by a long shot.' In an article in the Chronicles of Higher Education, entitled 'Building a Pathway for Occupational Students', ${ }^{(1)}$ it was noted that '...employers increasingly demand workers who have not only technical expertise, but also skills in language, communication, problem solving, and applied math.' Further 'The National Science Foundation's Advanced Technological Education program encourages stronger science and mathematics instruction in community-college technology programs and promotes partnerships between high schools and community colleges and between two-and four-year colleges to improve articulation among them all.' Two papers in the Journal of Engineering Education cited the need to expose 
engineering students to relationships between technology and society. The papers, entitled 'A History of Science and Technology Course for Engineering Students' ${ }^{\text {(12) }}$ and 'A Course in Technology and Society for Engineering Students' ${ }^{\text {(13) }}$ recommend, among other things, the historical development of science and technology in Western Civilization, and that engineering students should have a sense of the origins of their chosen profession in conjunction with present-day societal issues. A Techdirections article entitled 'The Emerging Field of Nanotechnology', ${ }^{(14)}$ notes that this technology '...could very well play a major role in economic and industrial growth in and competition among the world's leading nations.' The IEEE Singapore Section is organizing an IEEE Conference on Emerging Technology, and the theme is on Nanoelectronics. The October 2004 Prism has an article entitled 'Sweating the Small Stuff' ${ }^{(15)}$ and notes that 'Nanotechnology offers great promise for improving health and cleaning up the environment, and schools are scrambling to figure out how to teach it.' Also, 'Money is flowing into nanotechnology research from all sectors, public and private. And with funding going to education as well, industry hopes that the workforce will grow in step with their businesses - proving that the very small has potential to create big things.' In correspondence with the Listserv, I received a list of 18 colleges or universities that offer courses or a program in Alternative Energy.

ASEE's International Engineering Education Digest ${ }^{(16)}$ cites the National Academy report urging engineering education reform in the following manner. Consider the master's degree as the professional degree; insure that engineering faculty have industry experience; and provide the public with more information about engineering and engineering education to de-mythicize and make engineering more attractive to prospective students. In a Letter From The Chair ${ }^{(17)}$ of the ME Department at Ohio State University, it was stated that '...in teaching at the undergraduate level, we've undertaken significant planning for department-wide curriculum reform by involving more effective incorporation of microscopic and macroscopic perspectives...' and have '... implemented initiatives that include expansion of industrially-sponsored senior capstone design projects...'. The August 2005 issue of The Michigan Professional Engineer devoted that issue to environmental concerns. ${ }^{(18)}$ In the Johns Hopkins Magazine, an article entitled 'Curriculum Changes are Key to Diversity in Engineering Education', (19) noted that 'evidence is mounting that diversity in engineering student bodies is backsliding rather than improving', and that the key to the solution '...is revamping the curriculum-for example, emphasizing engineering coursework that appeals more to women and minority students, including case studies in which engineering is used to study diseases, improve education, or clean up city toxic waste sites.' In The Global Engineer, ${ }^{(20)}$ the Dean of Engineering at Purdue University stated '... that the U.S. engineer beyond 2020 will have to address a totally different set of problems from the ones we try to solve today', and '... will have to know how to address or solve a variety of problems, from creating means for communication between indigenous groups, to solving poverty, to providing transportation, to addressing the environment, to accommodating new technology breakthroughs in solutions, to becoming accustomed to a technology progress rate at a $10 \mathrm{X}$ to $100 \mathrm{X}$ of today's rate.' In 'Engineering: Trends and Opportunities Within the Industry', ${ }^{(21)}$ The Black Collegian Online states that we can better prepare '...engineers as industrial leaders...by placing emphasis on professional 
skills such as communications, project management, and team leadership'. Further, 'It is becoming more important that engineering be more diverse, not only because of the changing demographics, but because diversity enriches engineering.' It was also noted that '...good internships are important to begin understanding the engineering profession.' A feature article entitled 'The End of the M.E.?', ${ }^{(22)}$ in Mechanical Engineering, states that although 'Mechanical engineers control most of the rest of our economy', '...electric drives are taking over because an electrical bus can convey far more power in much smaller, lighter conduits, and do it far more precisely and reliably, than even the best designed mechanical drivetrain'. Further, 'The transformation is already well under way in the car's peripheral systems'. At the IEEE-USA Biennial Careers Conference, in an article entitled 'An Action Agenda for Engineering Curriculum Innovation', ${ }^{(23)}$ it was stated that we need more innovation in engineering programs with better integration of subjects; and to adopt a more innovative and entrepreneurial approach to education. Further, some changes in engineering practice that are occurring include: globalization, design for environment, concept-to-product time shortened, and frequent job and company changes. In IEEE-USA_Today's Engineer, an article entitled 'Engineering Education Evolves', ${ }^{(24)}$ states that 'U.S. engineering education is under as much pressure from globalization as many industries', and that 'One way is addressing the retention problem by encouraging students to maintain other interests such as music. That's a change from many universities where non-engineering hobbies are sometimes viewed as wasteful. Normally there's a subtle message to buy a laptop and sell the cello. We tell students to hang onto the cello'.

\section{Current Efforts}

The following college data is offered to show what is currently being taught and/or reviewed.

The Department of Mechanical Engineering at the California State University, Fullerton currently has four areas of specialization: Design and Materials for Manufacturing; Robotics, Controls, and Automated Manufacturing; Thermal and Fluids Engineering; Power and Energy. Their curriculum includes Mechatronics, Computer-Aided Engineering, and a variety of technical electives. Roger Williams University tailors its engineering program to suit a specific major, considers interdisciplinary interaction, and integrates lab experiences.

The Pratt School of Engineering at Duke University has a 'Pratt Vision 2010'(25) which is a 10-year comprehensive plan whose '...goal is to create a culture that nurtures interdisciplinary research and breakthroughs in engineering design, the basic and applied sciences, and medicine, resulting in new products, processes, diagnostic techniques, and therapies for improving the human condition and the environment.' Their research will make major investments in four cross-department strategic initiatives: Photonics and communications, bioengineering, materials engineering and sensors and simulators.

Eva Pell, Vice President for research and Dean of the graduate school at Pennsylvania State University, said that nearly 60 percent of basic research at universities funded by the federal government is now in life sciences. She said that funding for engineering and 
the physical sciences has declined, and cited a recent study showing that published papers by Western European physicists now outnumber those by U.S. authors.

The College of Engineering at Carnegie Mellon University, in 'The Carnegie Mellon Engineer in the $21^{\text {st }}$ Century, ${ }^{(26)}$ states that their more specific objectives include the following. 'Broadly educate our students, but also provide training in specific areas. Provide a flexible curriculum that allows students to make diverse choices and follow unique career paths. Provide a firm foundation for continuing education'. The highlights of their curriculum in the College of Engineering includes: four to six unrestrictive elective courses; engineering courses begin with the first year; each department teaches an Introductory Engineering Elective and every first year engineering student must elect one such course per semester.

Ohio State University provided a 'Proposal for Revising the General Education Component of Engineering Undergraduate Curricula.' ${ }^{(27)}$ It is based on an Outcomes Assessment Plan for General Education in Engineering that the College of Engineering has been engaged in since 1998. Its implementation was planned for Autumn Quarter, 2005.

Purdue University, in their 'Purdue's Future Engineer: Designing Curricula for the $21^{\text {st }}$ Century: Summary and Status, ${ }^{(28)}$ organized a Curriculum Reform Task Force '...charged with developing a blueprint that will guide Engineering's curriculum design and reform to ensure that we will be preeminent in educating the next generation of engineers and engineering leaders'. Their 'internal drivers' include ABET objectives and continuous improvement; a new Dept. of Engineering Education; and a drop in employer ranking of students. Their 'external drivers' include new and multidisciplinary technologies; rate of technological change; globalization; workforce issues (declining interest among U.S. students: interest down since 1991; slow progress on diversity; engineering students working in other fields; offshoring).

'The New Mechanical Engineering Curriculum at the University of Michigan'(29) was found in the Journal of Engineering Education. It describes the new undergraduate program in the Department of Mechanical Engineering and Applied Mechanics. 'The new curriculum consists of three integrated courses in Design and Manufacturing, two laboratory courses, and several redesigned courses in the Engineering Sciences. The redesigned program provides students with extensive hands-on experience, a comprehensive experience in teamwork and technical communication, and the opportunity to exercise and develop their creativity'. The following objectives are to be addressed in the new curriculum: experience with complex mechanical devices; teamwork and communication skills; customize the undergraduate degrees; introduce a sophomore level course in Design and Manufacturing; consolidate all required laboratories into a junior and senior lab sequence; and introduce a Freshman Engineering class.

The Colorado School of Mines undertook a pilot program...'intended to increase the retention and graduation of a group of "average" engineering students. Called 
Connections, the program focused on integrating the first-year curriculum while maintaining separate courses and on increasing the sense of community among student and faculty participants'. This is described in the Journal of Engineering Education article entitled 'The Effect of a First-Year Integrated Engineering Curriculum on Graduation Rates and Student Satisfaction: A Longitudinal Study. ${ }^{(30)}$ From surveys, students felt that interactions with faculty and peers were very important. This led to block scheduling so that groups of first-year students take at least 2-3 courses together, i.e., integrating the first year in 'connection modules'.

'New Programs Welcomed at Faculty Meeting' ${ }^{\text {(31) }}$ from the Massachusetts Institute of Technology News Office. A new undergraduate course in biological engineering will teach engineering entirely in the context of biology. Also, there was a merging of the Department of Mechanical Engineering and the Department of Ocean Engineering. 'The merged department's educational programs will include an undergraduate major with a specialization in ocean engineering and a continuing commitment to several important graduate programs...'

\section{$\underline{\text { Industry Survey }}$}

Requesting recommendations for a new engineering program from industrial/manufacturing sources.

- A major impetus on creative out-of-the-box brainstorming teaching.

- How to look at a problem from all angles.

- Cost control software based

- Do not teach only automotive engineering!

- Program should be based on industry needs. The programs should include hard deliverables and not just planning and studies.

- Mechanical functionality followed by design/CAD. Also strong in fluid handling.

- Tie-in with industries for summer internships. Hands-on is big factor.

- Practical, hands-on experience is necessary so that upon graduation, the engineer will have first-hand knowledge of what the users of the technology or skilled trades manufacturing personnel will face.

- Strong CAD/CAM software background.

- As much hands-on as possible in that field before going out in the field.

- America is falling behind the world not because of a lack of computer design, etc., but because of a reliance on it. We need more hands-on experience and knowledge.

- Hire instructors with hands-on experience who are currently working in the field - only.

- As a 2001 graduate of the Manufacturing Technology program at EMU, I can only recommend that the university continue to provide a first class experience to its customers (students).

- Engineers should also be able to read and write and compose letters and technical descriptions, etc. that can be implemented by the recipient. Many 
people that have applied for a job cannot read or write or have a good command of English and composition.

- The program should include working in the field. They need to understand what a lathe or mill can do.

- Basic engineering fundamentals combined with labs that require that the students actually make things. Using industry experts in adjunct roles could be beneficial.

- Don't forget about sensor technology in manufacturing processes, quality assurance systems, lean manufacturing and advanced materials and processes.

- Strong emphasis on current industry issues. Heavy emphasis on manufacturing processes in order to assure proper up-front engineering.

- Design engineering with style, safety. Rethink new equipment usages. Develop new ways of doing things.

- Basic Ergonomics is a plus in manufacturing

\section{Industry Survey}

Requesting recommendations for a new engineering program from engineering companies/sources.

- Up-to-date software: Catia \& Unigraphics. Also a bit of management training would be good. Also, I find that verbal communication is OK but written communication is poor.

- All engineers need to have some hands-on experience. Classroom instruction is good, but without field experience and knowing the product, they are already behind when they go to work.

- Catia, Unigraphics courses built into the curriculum.

- The United States is very poor when preparing mechanical and electrical engineers for the Construction/Design industry. Offer courses or electives. Talk about FE and PE exams, etc. Very Important!

- Environmental. It is extremely difficult to find engineers with design capability for remediation systems.

- Faculty to have current industrial experience. Program to be ABET accredited. Tackle real-world problems.

- Most important is they are good teachers/communicators. Under the name MET, I think it would be good to model a design course of studies modeled after what is taught at the school in Hamburg, Germany. These young ME students learn how to design car bodies and components.

- Do not overlook the area of RF applications (e.g., Voice, Data, RFID)

- More field trips and guest lectures from industry experts. Focus on design coupled with analysis.

Computer Usage Recommendations

Listserv Survey for ET and Engineering Programs 
- Adopt MATLAB as basic language required of all CET, EET and MET students.

- The Mechanical Engineering Department at MSOE houses both ME and MET programs. This has allowed many curriculum and course improvements made in one program to be adapted for the other. In the area of computing, the ME program had also seen difficulties in a $\mathrm{C}++$ course (the same course taken by MET students) and addressed the problem by creating a freshman-level computing class utilizing MATLAB and Excel. The students were still required to take the $\mathrm{C}++$ class. A second freshmanlevel course was later added, with MATLAB used to create programs to drive simple hardware from the students' PC's.

- If you are involved in Rapid Prototyping and Additive Manufacturing, you would want to look at "Magics" software from Materialise of Belgium.. This is the industry standard for fixing CAD drawings for the additive process.

- I recommend AutoCad and ProE for design courses. PATRAN/NASTRAN add a lot to strength of materials classes. Also, ADAMS, which is the product of Mechanical Dynamics, Inc. of Ann Arbor, goes good with Dynamics classes.

- Keep AutoCad for early drawing/CAD work and incorporate in various course design projects. Change from $\mathrm{C}++$ to something like MATLAB or MATHCAD or Visual Basic for the programming course. $\mathrm{C}++$ is a language that Electricals need but I do not think it is the right choice for Mechanicals. MATHCAD is a great tool for engineering problem solving.

- I strongly recommend that you try MATHCAD.

- SolidWorks for graphics. Algor for FEA in Strength of Materials. For Dynamics of Machines, we use several applications that come with the text we use, Design of Machinery by Norton, plus the full version of 2D Working Model.

- We are teaching AutoCAD, Inventor, SolidWorks and Pro/E.

- I work for an aerospace firm and use Mathworks' product suite (MATLAB, Simulink, etc.) for controls analysis, MSC.ADAMS for separation and dynamics analyses, and Labview for instrumentation. Pro-E and NASTRAN are dominant in the mechanical engineering side of my company.

- I suggest the Dassault products CATIA, Solid Works and Smart Team.

\section{Classified Advertisements for Engineers}

We examined the weekend classified sections of the Ann Arbor News and Detroit Free Press to determine the (consistency of) demand for engineering activity. Over a period of several weeks there were, on the average, 30 advertisements for engineering positions. These positions were for a variety of activities: Space Systems, Product Engineering, Powertrain, Ergonomics, Electronics, Robotics, Manufacturing, Construction, Sales, 
Vehicle Dynamics, etc. This indicates that a wide variety of engineering expertise is desired in our region (southeast Michigan).

\section{Summary}

Academic and national institutions are currently engaged in a comprehensive review of engineering programs in light of global technological changes and developments that can markedly affect the manner and form that engineering programs will be taught in the near future. We will briefly and individually list many of the considerations and factors that may determine current and future trends in engineering programs.

- Communicate both cross-disciplinary and cross-culturally.

- Prepare for political, social and economic responsibilities.

- Embrace continuing education.

- Work in multidisciplinary product design teams.

- Control the properties of materials at the nanoscale.

- A successful solution requires an equal application of information, energy and materials technology.

- Have project-centered courses.

- Programs should be fundamental at its core.

- Start with an ME-based program that has a principal design function.

- Design should be the backbone of engineering education.

- Find ways to reverse trends and attract a major talent pool to U.S.

- A balanced engineering degree will provide a springboard to other careers.

- More biology and interest in economics and social sciences.

- Mechatronics and Computer-Aided Engineering.

- Interdisciplinary research.

- Improve the human condition and environment.

- Bioengineering and materials engineering.

- Life sciences is currently receiving major funding.

- Major movement in UG curriculum to include Ethics.

- Outsourcing creating downward pressure on U.S. engineering salaries.

- Stronger science and mathematics instruction in community colleges.

- Expose engineering students to relationships between technology and society.

- Nanotechnology could play a major role in economic and industrial growth.

- Engineering faculty should have industrial experience.

- Industrially-sponsored senior design capstone projects.

- Program should be based on industry needs.

- Major impetus on creative/brainstorming teaching.

- Use industry experts in adjunct roles.

- Need to have hands-on experience.

- Up-to-date software.

- Programs in Alternative Energy. 


\section{Conclusion.}

Preparation for and development of a new engineering program should carefully consider the factors that are discussed in this overview. The goals that are projected by many academic and national institutions will require a considerable re-development of the educational process: new labs, equipment, faculty, courses, teaching methods, etc. We need to decide whether to consider a new engineering program in view of all the current activity towards 2020, or initially fashion an engineering program that has current possibilities and, possibly, future limitations. If, for example, we decide to engage in the latter approach, we would recommend that we consider an ME-based program with a principal design function. The (ME) program may want to consider the incorporation of the following:

- Cultural/language requirements

- Ethics

- Mechatronics

- Bio-engineering

- History: Science \& Technology

- Environment

- Nanotechnology

- Alternative Energy

- Interdisciplinary

- Project-centered

- Design-centered

- Principal/fundamental areas of knowledge

\section{BIBLIOGRAPHY}

1. National Academy of Engineering, The Engineer of 2020: Visions of Engineering in the New Century. The National Academies Press, Washington, DC, 2004.

2. Peercy, P.S., "The Changing Face of Engineering," Engineering Trends-Editorials, November, 2004.

3. Schmidt, P.S., "Mechanical Engineering 2004-2005 Plan to the College,"ASME Congress, 2003.

4. Schmidt, P.S., "Managing a Major Curriculum Reform Effort in a Large Research University," Proceedings of IMECE2003 International Mechanical Engineering Congress and Exhibition, Washington, DC, November, 2003.

5. Dym, C., "The Evolution of Engineering Curricula," Clockworks, The Cooper Union, Winter, 2004.

6. Clough, G.W., "The Engineer of 2020,” Clockworks, The Cooper Union, Spring-Summer, 2004.

7. Lee, E.A., Messerschmitt, D.G., "Engineering an Education for the Future," IEEE, January, 1998. 
8. National Science Foundation, New Directions in Mechanical Engineering. Wokshop, Big-TenPlus Mechanical Engineering Department Heads, Florida, January, 2002.

9. Director, S.W., “2020: It’s Sooner Than You Think,” ASEE Prism, January, 2005.

10. Hirea, R., ASME Sponsored Forum, www.asme.org/gric.

11. Bailey, T., Jenkins, D., "Building a Pathway for Occupational Students," Chronicles of Higher Education.

12. Kett, I., “A History of Science and Technology Course for Engineering Students," Journal of Engineering Education, July, 1998.

13. Dick, K.J., Stimpson, B., "A Course in Technology and Society for Engineering Students," Journal of Engineering Education, January, 1999.

14. Sabulski, C.P., "The Emerging Field os nanotechnology,” Techdirections, October, 2004.

15. Wu, C., "Sweating the Small Stuff," ASEE Prism, October, 2004.

16. ASEE's International Engineering Education Digest, March, 2005.

17. Srinivasan, K., "Letter From the Chair," The Exchange, The Ohio State University, Summer, 2005.

18. The Michigan Professional Engineer, August, 2005.

19. Simpson, J.C., "Curriculum Changes Are Key to Diversity in Engineering Education," John Hopkins Magazine, October, 2005.

20. Katehi, L., "The Global Engineer,” Purdue University, July 22-23, 2004.

21. Bunkley III, C.B., "Engineering: Trends and Opportunities Within the Industry," The Black Collegian, Online, September, 2005.

22. Huber, P.W., Mills, M.P., "The End of the M.E.?,” Mechanical Engineering, May, 2005.

23. Smerdon, E.T., "An Action Agenda for Engineering Curriculum Innovation," $11^{\text {th }}$ IEEE-USA Biennial Careers Conference, San Jose, California, November, 2000.

24. Costlow, T., “Engineering Education Evolves," IEEE-USA Today's Engineer, September, 2005.

25. Pratt Vision 2010, Pratt School of Engineering, Duke University, Progress Report, 2005.

26. The Carnegie Mellon Engineer in the $21^{\text {st }}$ Century, College of Engineering at Carnegie Mellon University-Educational Objectives, October, 2005.

27. Proposal for Revising the General Education Component of Engineering Undergraduate Curricula, College of Engineering, The Ohio State University, June, 2003.

28. Purdue's Future Engineer: Designing Curricula for the $21^{\text {st }}$ Century: Summary and Status, Purdue University, August, 2005.

29. Gretar, T., "The New Mechanical Engineering Curriculum at the University of Michigan," Journal of Engineering Education, July, 2001. 
30. Olds, B.M., "The Effect of a First-Year Integrated Engineering Curriculum on Graduation Rates and Student Satisfaction: A Longitudinal Study,” Journal of Engineering Education, January, 2004.

31. New Programs Welcomed at Faculty Meeting, MIT News Office, February 23, 2005.

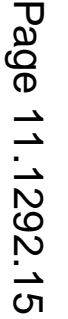

